\title{
Küreselleşen Dünyada Çokkültürrlülük ve Yabancı Dil Eğitimi
}

DOI: $10.26466 /$ opus.651385

*

\section{Elif Ateş ${ }^{*}$ - Halil Aytekin ${ }^{* *}$}

*YL Öğrencisi., Ondokuz Mayıs Üniversitesi, Eğitim Bilimleri Enstitüsü, Samsun/Türkiye E-Posta: eates1987@gmail.com ORCID: 0000-0001-7926-3548

** Prof. Dr., Ondokuz Mayıs Üni., Eğitim Fakültesi, Yabancı Dilller Eğitimi Böl., Samsun/Türkiye E-Posta: haytekin@omu.edu.tr

ORCID: $\underline{0000-0001-9150-472 X}$

\section{Öz}

Günümüzde, küreselleşmenin bir sonucu olarak kültürel ve dilsel etkileşim kaçınılmaz olmuş ve en az bir yabancı dil öğrenmek zorunlu hale gelmiştir. Çokkültürlü yaşama anlayışını destekleyen, diğer kültürlere saygı ve hoşgörü ile yaklaşmayı, farklı ırklardan olan insanlarla etkileşimde olmayı teşvik etmek üzerine kurulu bir yabancı dil eğitimi ve öğretimi programı olan Diller için Avrupa Ortak Başvuru Metni'nde, yabancı dil eğitimi ve öğretimi sürecinde hedef dilin konuşulduğu ülkenin bazı kültürel ögelerinin de öğretilmesi önerilmektedir. Nitekim dil ve kültür olgusu küreselleşen dünyada üzerinde durulması gereken en önemli iki unsur olarak ortaya çımaktadır. Çünkü iletişim dil ile gerçekleşir, birbirini anlamak ve birlikte hareket etmek karşılıklı anlayışı gerektirir. Çokkültürlü eğitim fikri, geleceğin dünyasında, farklılıkları engel olarak görmeyen, sinırların ötesini görerek ve düşleyerek eorensel bir bakış açısııla dünyayı daha yaşanılır kılmaya çalışan ve onu koruma refleksiyle hareket edip barışı destekleyen, öteki kültür ve dillere hoşgörülü̈, fakat farklı dil ve kültürlerin yaşaması için, çeşitlilik içerisinde kendi dil ve kültürüne sahip çıkıp, yaşatmayı kendine ilke edinmiş dünya vatandaşları yetiştirmek adına atılmış en uzlaşmacı ve fütürist eğitim modeli olarak görülmektedir. Çalışma nitel araştırma tarama modeliyle ile yürütülmüş olup, küreselleşme bağlamında çokdillilik ve çokkültürlülük, dil kültür-ilişkisi, çokdilliğin ve çokkültürlülü̈̆̈̈n modern dünyadaki yeri ve çokkültürlü eğitimin yabancı dil eğitimi ve öğretimine yansımaları eleştirel bir bakış açısıyla incelenmiştir.

Anahtar Kelimeler: Çokküktürlülük, küreselleşme, yabancı dil, eğitim 


\title{
Multiculturalism and Foreign Language Education in A Globalized World
}

\begin{abstract}
Today, as a result of globalization, cultural and linguistic interaction has become inevitable and learning at least one foreign language has become compulsory. In the Common European Framework of Reference for Languages, which is a foreign language education program that supports multicultural life and encourages to respect and tolerate other cultures and to interact with people of different races, it is recommended to teach some cultural elements of the country where the target language is spoken in the process of foreign language teaching/learning. As a matter of fact, the phenomenon of language and culture emerges as the two most important elements to be emphasized in the globalizing world. Because communication takes place through language, understanding each other and acting together requires mutual understanding. In the world of the future, the idea of multicultural education is seen as the most accommodating and futurist education model in order to educate global citizens who do not see differences as obstacles, who try to make the world more livable with a universal perspective by seeing and imagining beyond borders, and who act with the reflex of protecting it and supports the peace, who are tolerant of other cultures and languages. The study was carried out with a qualitative research screening model. In the context of globalization, the relationship between language and culture, the place of multilingualism and multiculturalism in the modern world and the reflections of multicultural education on foreign language education and teaching are examined with a critical perspective.
\end{abstract}

Keywords: Multiculturalism, globalization, foreign language, education 


\section{Giriş}

Küreselleşen dünyada, teknoloji sayesinde insanlar arasındaki sınırların hızla kalkmasıyla, toplumlar arası etkileşim kaçınılmaz hale gelmiştir. İletişimin ve ulaşılabilirliğin kolaylığı arkadaşlık, iş ortaklığı, eğitim gibi karşııklı iletişime ve etkileşime dayanan ticari ve bireysel ilişkiler farklı ırktan insanların aynı ortamda bulunmalarına, birlikte hareket etmelerine veya birlikte çalışmalarına olanak sağlamıştır. Öyle ki başka bir ülkenin vatandaşı ile o kişinin bulunduğu ülkeye gitmeye gerek kalmadan teknolojinin sağladığı imkanlarla her türlü iş/eylem gerçekleştirilebilmektedir.

Uluslararası iletişimin ve etkileşimin neredeyse zorunlu hale geldiği günümüzde en az bir yabancı dil bilmenin gerekliliği gün yüzüne çıkmış ve ülkeler eğitim politikalarını bu yönde şekillendirmeye başlamışlardır. Ethnologue dil veri tabanına göre, dünyada 141 resmi, 7,111 konuşulan dil bulunmakta, dünya üzerinde en çok konuşulan diller ise sırasıyla ingilizce, çince, hintçe, ispanyolca ve fransizca olarak gösterilmektedir. Günümüzde ingilizcenin dünya dili olması sebebiyle şüphesiz en çok eğitimi ve öğretimi yapılan dil ingiliz dili olarak kayıtlara geçmiş bulunmaktadır. Fakat geleceğin küreselleşen dünyasında her bireyin ortak eylem planında yer almasını sağlamak amacıyla, ülkemizde ve dünyada ingilizcenin yanı sıra ikinci ve üçüncü yabancı dil olarak Almanca, Fransızca, Çince, İspanyolca, gibi diller müfredatta yerlerini almakta ve bu dillerin konuşulduğu ülkeler ile bireysel, kurumsal, toplumsal ve siyasal ilişkiler kurma planları yapılmaktadır.

Bunun yanı sıra, küreselleşen dünyada yaşadığımız gezegen için küresel sorunlara karşı birlikte hareket edebilen, "küresel vatandaşlar!" yetiştirmek bazı ülkelerin ortak kaygısı haline gelmiştir. Burada tırnak içerisinde verdiğimiz "küresel vatandaş" kavramına açıklık getirilmediği takdirde yanlış anlaşılmalara sebep olacaktır. En basit tanımıyla küresel vatandaş, dünyanın öne çıkan sorunlarına duyarlılık gösteren ve uluslararası ölçekte inisiyatif alabilen vatandaş modelidir. Bu kabul edilebilir bir yaklaşımdır. Ancak küresel vatandaş kavramıyla insanların kendi kültürlerini terk ederek yeni dünyanın dayattığ 1 küresel kültürü benmsemeleri isteniyorsa bu yaklaşım ulus devletlerin korumaya çalıştı̆̆ı değerler için son derece tehlikelidir.

Yabancı dil bilgisi uluslararası ilişkilerde ülkelerin geleceğin dünyasında söz sahibi olmasında en önemli kıstaslardan birisi olarak ortaya çıkmaktadır. Çünkü iletişim dil ile gerçekleşmektedir ve birlikte hareket etmek karşılıklı 
anlayışı dolayısıyla ötekinin kültürü hakkında bilgi sahibi olmayı gerektirmektedir. Bu bağlamda Avrupa Konseyi bir yabancı dili öğretirken hedef dilin bazı kültürel ögelerinin de öğretilmesinden yana çokkültürlü eğitimi destekleyen bir program geliştirmiş ve uygulamaya koymuştur.

2001 yılında Avrupa Konseyi tarafından düzenlenen Diller İçin Avrupa Ortak Başvuru Metninde, bireysel bağlamda çok dillilik (plurilingualism) üzerinde durulmuş, öğrenenin sosyal bir aktör olarak görüldüğü Eylem Odaklı Yöntem çerçevesinde bir yabancı dil eğitimi ve öğretimi öngörülmüştür. Metinde aynı zamanda sosyal bağlamda çokdillilik (multilingualism) ve çokkültürlülük (multiculturalism) kavramlarının altı çizilmiş, farklılıklardan çok benzerliklere dikkat çekilmiştir. Bu yaklaşımda sosyal bağlamda çokdilliliğin yanı sıra bireysel bağlamda birden fazla yabancı dilin bilgisine işaret edilmektedir." 'Birey bağlamında' çok dillilik, bir dizi dilin bilinmesi ya da bir toplumda aynı anda farklı dillerin kullanılması anlamına gelen 'sosyal bağlamda' çokdillilikten, farklıdır. Sosyal bağlamda çokdillilik okul ya da eğitim kurumlarında öğrenciye sunulacak yabancı dil bilgisinin çeşitlendirilmesi, öğrencinin birden fazla yabancı dil bilmeye yönlendirilmesiyle, ya da uluslararası iletişimde İngilizcenin baskın rolünün sınırlandırılması yoluyla kazanılabilir. Buna karşın birey bağlamında çok dillilik, yerel dil dışındaki toplumların dillerine kadar -okulda veya doğrudan deneyimle de kazanılabilir(kültürel bir bağlamda) genişlemektedir. Birey, bu dilleri ayrı zihinsel bölümlerde tutmaz, ancak bu dillerin karşlıklı iletişim ve etkileşim içinde olmasını sağlayacak bir iletişim yeteneğine sahiptir. Birey, farklı durumlarda bir konuşmacıyla etkili iletişim kurabilmek için sahip olduğu yeteneğin farklı özelliklerini kullanabilecek esnekliğe sahiptir" (MEB Çeviri Komisyonu, 2009: 3). Bu bağlamda bir çok dillilik (plurilingualism), küreselleşen dünyada sosyal bir aktör olması öngörülen öğrenenin ortak dünya dili olan ingilizcenin yanında farklı diller hakkında da bilgi edinmesini ve o dillerde etkin bir şekilde iletişim kurabilmesini amaçlar.

\section{Küreselleşmenin Dil Ve Kültüre Yansımalanı}

Günümüz dünyasında ülkeler arasında ekonomik, siyasi, sosyal ve kültürel ilişkiler her geçen gün biraz daha artış göstermektedir. Ülkelerarası ilişkilerin artmasıyla birlikte, ülkeler iç ve diş politikalarını yeniden gözden geçirmek ve dizayn etmek zorunda kalmış, geleceğin küresel dünyasında söz sahibi 
olma ve var olan statükolarını koruma kaygısına düşmüşlerdir. Yeni dünyanın dayattığı koşullara maruz kalan insanlar ya bir araya gelmenin yollarını aramakta ya da birbirlerinden uzaklaşmaktadırlar. Bu tür ilişkiler tamamen karşılıklı menfaat ilişkileriyle de ilintilidir. Ama genel eğilim, farklılıklara rağmen birbirini kabullenme ve barış içinde yaşama arzusudur.

İnsanlar gibi toplumlar da farklılıklar gösterirler. Her toplumun kendine has bir kültürü vardır. Barış içinde yaşama arzusunun temel şartı diğerinin kültürünü yok saymamaktan geçer. Çünkü kişi ve toplumlar, varlıklarını kültürleriyle gösterirler. Kültür, bir ulusun kimliğidir. Ulusal kimliğin en önemli belirleyicisi olan kültür, içerisinde toplumların kendilerini ifade edecekleri değerleri barındırır. Dil ise bir bilgi aktarım aracı olmanın ötesindedir. İnsanlar dünyayı dil ile anlamlandırır. Kültüre bir dil sayesinde ulaşılır ve bir kuşaktan diğerine yine dille aktarılır.

Küresel dünya tek tip bir anlayış üzerine dayanmamaktadır. Zira dünya artık çokkültürlülük ve çokdillilik kavramlarını tartışmaktadır. Küreselleşme, farklı dil ve kültüre sahip farklı ırklardan insanları bir araya getirmiş, bu birliktelik insanları, ırkçı yaklaşımlar yerine karşılıklı hoşgörü anlayışını benimsemeye yöneltmiştir. Nitekim birlikte yaşayıp birlikte hareket edebilmek için çatışma yaratacak düşünce ve davranış biçimlerinden uzaklaşmak ve ötekinin farklılığına saygı duymak dünya toplumunun geleceği için hayati önem taşımaktadır. Bununla birlikte, dil ve kültür çeşitliliği bir zenginlik olarak görülmekte, ulusal kimliklerin yaşamaya devam etmesi ve zamanla yitip gitmemeleri veya baskın kültürlerin hegemonyası altında başka formlara bürünmemeleri için her ülke kendi toplumu adına bazı dil ve kültür politikaları geliştirmek durumunda kalmıştır.

Her ulusun kültürü ve dili kendine özgüdür ve birbirlerinin tamamlayıc1sıdırlar. Dil, insanların birbirleriyle iletişim kurmalarını sağlayan yegane araçtır, kültür ise dilin derin yapısında kendini gösterir ve iletişimin bir parçası olarak insan ilişkilerindeki yerini alır. Diğeriyle birlikte yaşama ve diğerini anlama zorunluluğu, bugün insanları çokkültürlü eğitim kavramına götürmüştür. Çokkültürlülük 1960'lı yıllarda ABD'de ortaya çıkmış bir kavramdır. Dünyanın farklı bölgelerinden çok sayıda göç alan ve dolayısıyla heterojen bir toplum yapısına sahip olan $\mathrm{ABD}$, çokkültürlü yaşama adapte olmak adına birçok politika geliştirmiştir. Bu politikalar arasında eğitim alanında geliştirilen politikalar, ülkenin geleceği açısından atılan en büyük adımlar 
arasında yer almaktadır. Çünkü eğitim toplumu şekillendirmenin, belli anlayış, düşünce ve yaşam biçimlerini empoze etmenin ve hayata geçirmenin, k1sacası geleceğin toplumunu inşa etmenin en etkili yoludur. Eğitim aracıllğıyla birey önceden belirlenmiş amaçlar doğrultusunda değişir, biçimlenir ve yaşadığı toplumun yapısına uygun bir vatandaş haline gelir. "Durkheim'a göre eğitim, "toplumsal hayata henüz hazır olmayanlara yetişkin kuşaklar tarafından uygulanan bir etkidir. Amacı bireyde hem bir bütün olarak siyasal toplumun, hem de bireyin bağlı olduğu iş çevresinin kendinden istediği belirli sayıda fiziksel, entelektüel ve ahlâki yetenekleri meydana getirmek ve geliştirmektir" (Doğan, 2004: Aktaran Yıldırım, 2011, s.12). Çokkültürlülüğe adapte sürecinde de eğitim yadsınamaz bir öneme sahiptir. Çokkültürlü eğitim; bir fikir veya kavram, bir eğitim reformu hareketi ve bir süreçtir. Tüm öğrencilerin cinsiyetleri, sosyal sınıfları ve etnik, ırksal ya da kültürel özelliklerinden bağımsız olarak okulda öğrenme fırsatına sahip olmaları gerektiği fikrini içerir. (Banks, ve Banks, 2007, s.3) Bu bağlamda çokkültürlü eğitim, kapsayıcı, bütünleştirici ve birlikte hareket etmeyi destekleyen bir eğitim/öğretim yaklaşımıdır. Değişen ve gelişen dünyada çoğu eğitim programında kendine yer bulmuş, okullarda eğitim ve öğretimin çokkültürlü yaşamı destekler nitelikte yapılanmasına vesile olmuştur.

\section{Çok Dillilik ve Çok Kültürlülük}

Yabancı diller 1960'lı yıllara kadar kültürlü çevrelere, zenginlere ve birkaç özel mesleğe özgü iken bugün en çok konuşulan ve tartışlan konulardan biri haline gelmiştir. Dünya hızla değişmektedir. Son onyıllar incelendiğinde iletişimin farklı formlara büründüğü dolayısıyla da iletişim ve etkileşimde inanılmaz gelişmeler yaşandığı görülmektedir. Öyle ki dünyanın herhangi bir bölgesinde bulunan herhangi biri bilgisayar aracilı̆̆ıla tek bir tıklama ile hızlı bir şekilde bilgiye veya dünyadaki herhangi bir dille ilgili bir kaynağa kolaylıkla ulaşılabilmektedir. Telefon, elektronik posta veya mesajlaşma yoluyla dünyayla neredeyse parasız konuşulmakta, sınırların ötesine yapılan seyahatler artık daha hızlı ve ekonomik yapılabilmektedir.

Git gide daha fazla şirket uluslararası ölçekte aktif pozisyon almakta diğer ülkelerde iş yapmakta ve farklı dillerin konuşulduğu birçok ülkede mallarını tanitmakta, satmakta ve hizmet vermektedir. Bu şirketlerin görevi çeşitli va- 
sitalarla insanlarla iletişim kurmak ve onlara ürünlerini pazarlamaktır. Bu hedef doğrultusunda farklı coğrafyalarda ürünlerini pazarlayabilmek için hedef kitlenin diline ve kültürüne uygun pazarlama teknikleri geliştirmişlerdir.

Tüm dünyayı içine alan bu gelişmelerin en güzel örneği Avrupa'da yaşanmaktadır. Bilindiği gibi Avrupa Birliği küreselleşmenin doğurduğu ekonomik ve siyasi düzeyde birlikte hareket eden bir topluluğun adıdır ve dünyadaki tüm bu gelişmelerin merkezinde söz sahibi konumdadır. Bu topluluğun amacı hem $A B$ ülkelerinde hem de dünya genelinde özgürlük, demokrasi, insan hakları ve hukukun üstünlüğü değerlerini garanti altına almak ve yaymak, her türlü ayrımclıkla mücadele etmek, iklim değişikliği ile mücadele etmek, çevreyi en üst düzeyde korurken ekonomik büyümeyi sürdürebilmek, yasadışı göç, uluslararası terörizm, insan, silah ve uyuşturucu kaçakçllığı gibi suçlarla etkin biçimde mücadele etmek olarak sıralanabilir.

Tüm bu uluslararası gelişmelerin merkezinde dil yer almaktadır. Bu bize: "Eğer bir şeyler satmak istiyorsan, müşterinin dilinden anlamalısın" sözünü çağrıştırmaktadır. Son zamanlarda yapılan çalışmalar bu yaklaşımı doğrular niteliktedir. Mesela 2003'te Alman Ticaret Odasının İspanya pazarı hakkındaki bir çalışması; İspanyol şirketlerinin Almanya ile ticaretlerinde özellikle Almanca kullandıklarını ve bu şirketlerin İngilizce konuşarak ticaret yapmaya çalışan diğer İspanyol şirketlerine göre daha iyi işler yaptıklarını ortaya koymaktadır. David Graddol (2006) İngilizcenin geleceği konulu çalışmasında, başlıca 14 gelişmeden biri olarak gördüğü ingilizcenin ekonomi alanında üstünlügünün 2050 yılına doğru azalacağını ve günümüzde şimdiden Japoncanın, İspanyolcanın, Fransızcanın ve Almancanın git gide daha önemli olduğunu öngörmektedir (Andriuškevičienè ve Kazlauskaitė 2019, s.64). (http://www.goethe.de/ges/spa/prj/sog/mup/fr3249600.htm). Neticede, şu an için ingilizcenin hakimiyeti tartışılmaz. Ancak iş dünyasındaki gelişmeler, ilişkilerin sağlıklı yürütülmesi ve kalıcı olması için hedef pazarın dilinin mutlaka bilinmesi gerektiğine de işaret etmektedir. Yani geleceğin dünyasında tek başına İngilizce yeterli olmayacaktır.

Artık günümüzde yabancı dillerin bilinmesi sadece mesleki bir uğraş veya dışarıya yönelik temaslar için bir gereklilik olmaktan çok daha fazla bir kazanımdır. Zira insanlar çok renkli şehirlerde yaşamaktadırlar. Yabancı biri ile temas günlük yaşamın bir parçası haline gelmiş, göçler ve küresel hareketlilik ötekiyle ilişkiyi daha da zorunlu hale getirmiştir. Mesela Almanya'nın Stutgart şehri buna iyi bir örnektir: 581000 nüfusuyla Almanya'nın sekizinci şehri 
olan Stutgart'da 5 kişiden biri farklı bir pasaporta sahiptir. Bu şehirde üç kişiden biri Almanya'da doğmamıştır. Stutgart'da okul öncesi çağında olan her iki çocuktan biri göçmen bir aileden gelmektedir. Stutgart'da her iki evlilikten birinde en az iki eşten birinin alman pasaportu yoktur. Bu şehirde 120 farklı ülkeden 170'den fazla dil konuşan insan yaşamaktadır (http://www.goethe.de/ges/spa/prj/sog/mup/fr3249600.htm). Hemen şunu da ifade edelim ki Stutgart bir istisna değildir. Avrupanın birçok şehri bu tür farklı ırktan insanların yaşam alanına dönüşmüştür. Görünen odur ki sadece Avrupa değil Türkiye'de artık bu çokdilli ve çokkültürlü ortamı teneffüs etmektedir.

Mevcut koşullar, insanları bu yeni ortak yaşam tarzını kabullenmeye ve karşılıklı anlayışa mahkûm etmektedir. Yabancı dillerin öğretimi bu kapsamda önem kazanmaktadır. Bu tür bir girişim, çocukları ve gençleri diğer kültürlerle temas kurmaya iter ve onları, yani ister öteki deyin, ister yabancı olarak niteleyin, birbirleriyle ilişkiye sokarak şekillendirir. Bu yüzden Avrupa ülkeleri, diğer ülkelerle iki taraflı ilişkilerde olduğu kadar, çokkültürlü ve çokdillilik kapsamında da kendilerine uyum sağlayacak vatandaşlara ihtiyaç duymaktadır. Avrupa ve vatandaşlarına gereken şey, başka dil ve kültürleri anlama ve onlarla birlikte hareket edebilme becerisi göstermektir. Tam olarak Avrupa Komisyonunun isteği budur. Sadece tek dil öğretimi yeterli değildir. Her Avrupa vatandaşı kendi ana dili dışında en az iki yabancı dilde iletişim kurabilmelidir.

\section{Çokdillik ve Çokkültürlüğün Yabancı Dil Eğitimi ve Öğretimine Yansımaları}

Çokdilli ve çokkültürlü yaşamda, yabancı dil eğitimi ve öğretimi daha da bir önem kazanmıştır. Yabanc dil eğitimi ve öğretimine, küresel vatandaş yetiştirmek için ihtiyaç duyulan kazanımların dahil edilmesi ve bu yolla öğrenenlere hedeflenen vasıfların kazandırılması oldukça kolaydır. Nitekim, yabancı bir dil öğrenirken, kültürün göz ardı edilemeyecek bir yeri vardır. Kültürün dahil olmadığı bir dil dersinde, hedef dilin tam anlamıla öğrenimi ve öğretiminden bahsedilemez. Bir dili tüm yönleriyle öğrenmek, o dili konuşan toplumun üyelerinin, yazılı eserlerinde kullandıkları dilin yanı sıra, sosyal hayatlarında belirli yer ve durumlarda kullandıkları dilin de öğrenilmesi demektir. Nitekim dili yaratan sosyal hayattır. Öğrendiği yabancı dilin kültü- 
rünü tanıyan ve farklı yaşam biçimlerinin varlığından haberdar olan öğrenen, küresel bir vatandaş olma yolunda, çokdilli ve çokkültürlü yaşama bir adım atmış demektir. Bu nedenledir ki Diller İçin Avrupa Ortak Başvuru Metni, yabancı dil eğitimi ve öğretiminde, hedef dil ile birlikte, sosyokültürel bilgi çerçevesinde, dilin ayrılmaz bir parçası olan kültürün de öğrenene kazandırılması gereken bir bilgi olarak, yabancı dil eğitim ve öğretim programına dahil edilmesini önermiştir. Yine bu metinde, öğrenenin yabancı dil öğrenimi sırasında, hedef dilin konuşulduğu ülkeye ait hangi yeni kültürü öğrenmesi gerektiği sorusuna da şu başlıklarla açıklık getirmiştir: Günlük Yaşam, yaşam şartları, kişiler arası ilişkiler, değerler, inanışlar ve tutumlar, beden dili, sosyal (toplumsal) âdetler (gelenekler), törensel davranışlardır (MEB Çeviri Komisyonu, 2009, s.98).

Diller İçin Avrupa Ortak Başvuru Metninde, hedef dilde kültüre dair öğretilmesi amaçlanan, toplum için belirleyici olan bu özellikler, toplumun tüm sosyal yaşamını içine alır. Metin, hedef dilin ait olduğu toplumun kültürünü oluşturan, mikro düzeyde bir sistemi ifade eden bireyden, makro düzeyde bir sistemi ifade eden sosyal sinfflar, sosyal tabakalar ve kuruluşlara ve mezzo düzeyde bir sistemi ifade eden topluluk, grup ve organizasyonlara kadar, toplumun farklı kesimlerinin benimsediği konuşma biçimlerinden doğmuş, iletişim farklılıklarının da öğretiminin yapıldığ etmektedir. Bu noktada akla William Labov'un ayrılık kuramı gelmektedir. "Ayrılık kuramı bir bakıma dil değişkenliğinin dilbilim bakımından açıklanmasını kapsamaktadır. Bu kuram çerçevesinde öncelikle dilsel dizgelerin nasıl ve hangi işlevlere ayrıldığı inceleme konusu edilmekte; bununla ilişkili olarak ölçünlü tür yanında bölgesel, toplumsal, işlevsel dil türlerine de yer verilmektedir" (İmer, 1990, s.43). Dilin kendi içerisinde kullanılan bölgeyle ilişkili olarak farklılık göstermesinin yanı sıra dilsel toplulukların toplumdilbilim çalışmaları, modern dünyada dilsel çeşitliliğin yaş, cinsiyet, sosyal sınıf, ırk/etnik köken, kentsel/kırsal statü ve sosyal iletişim ağındaki konum gibi az sayıda sosyal değişkenle ilişkili olduğunu göstermektedir (Labov, 2010, s. 197). Dili etkileyen ve oluşturan bu değişkenler, o toplum içerisindeki dilsel farklılıklarla birlikte kültürel farklılıkları da beraberinde getirmektedir. Toplum içerisinde kendilerine yer bulmuş bu farklı konuşma biçimleri, o toplumun sosyal yaşamından etkilendikleri gibi sosyal yaşamını da etkilemektedir. Kendi içinde bir dinamiğe sahip olan dil, kitleleri etkileyebilme, yönlen- 
direbilme kapasitesine sahiptir. Tarih boyunca toplumun etki gücünün bireylere duyurulması için çeşitli iletişim ve etkileşim araçları kullanılmıştır. Dil, tüm etkileşim ve iletişim süreçlerinin başlangıcı ve ürünüdür. Hem kitle iletişim araçlarının hem de insan topluluklarının en önemli iletişim aracıdır. Dil ve iletişim olmasaydı belirli bir etkileşim alanı ve insan davranışlarını oluşturan kültürel ortam olmazdı (İsen ve Batmaz, 2002, s.173). Kültürlerarası diyalog ile derinlemesine sarsılan bir dünyada, göz ardı edilemeyecek bir güç ve etki aracı olan dil, kimlik ve iletişim arasında bir yerdedir. Bir dil öğrenilmeye başlandığında, dil ve kültür etkileşimi gerçekleşir. Dil, öğrenene sosyal etkileşimler ışığında öğretilir ve bunun sonucunda sosyolojik boyutuyla dilin yanında kültür de sunulmuş olur. Dil öğretimine kültürü de dahil etmek ve çokkültürlü yaşamı eğitim aracılığıyla teşvik etmek, geleceğin dünyasının belli bir ölçüde şekillenmesine katkıda bulunan bir tutumdur. Zira bir yabancı dili öğrenmek, yeni bir kültürü, yaşam tarzını ve farklı düşünce tarzlarını anlamak, yerellikten evrenselliğe bir adım atmak demektir. Kültürel unsurları, dilsel açıdan ele almak, öğrenenlerin diğer kültürlere açılmasını ve böylece daha tarafsız, daha hoşgörülü, daha saygılı birer küresel vatandaş olmalarını sağlayacaktır.

Dillere göre öğretim hedefleri farklılaşacağı için, XXI. yüzyıl eğitim kurumlarının hedefi her vatandaşın kültürel ufkunu ve iletişim düzeyini artırmak olmalıdır. Zamanın kullanımı içerisinde yabancı dile ayrılmış saatler çok sınırlı olduğu için, hedeflenmiş olan çok dillilik, öğretilen farklı dil hedeflerinin ayrımıyla olanaklı kılınabilir. İletişim düzeyi önceden edinilmiş dil bilgilerinden hareketle ve dil yakınlığından yararlanarak genişletilebilir. Öğrencilerin aynı dil ailesinden farklı dillerdeki yazılı veya sözel metinleri çözmeleri sağlanarak konuyu ve mesajını anlamalarına yönelik dersler verilebilir.

Çokkültürlü eğitim; bir fikir veya kavram, bir eğitim reformu hareketi ve bir süreçtir. Çok kültürlü eğitim, tüm öğrencilerin cinsiyetleri, sosyal sınıfları ve etnik, rrksal ya da kültürel özelliklerinden bağımsız olarak okulda öğrenme fırsatına sahip olmaları gerektiği fikrini içerir (Banks ve Banks, 2007, s.3). Çokkültürlü heterojen bir ortamda eğitimini sürdüren ve sosyal çevresinde gerçek ortamlarda farklı dil ve kültüre sahip insanlarla ilişkiler kuran öğrenen, iletişim ve etkileşim halinde olduğu kendi diline ve kültürüne yabancı insanları anlama şansına sahip olur. Çokkültürlü anlayışın hakim olduğu bir dil eğitimi, farklı insan topluluklarının tarihleri ve kültürleri hakkında bilgiler vererek öğrenenlerin hedef dilin ait olduğu kültüre karşı bir 
fikir sahibi olmalarına yardımcı olur, böylece öğrenen öteki kültüre yabancı kalmaz. Çokkültürlü bir eğitimle, farkındalık yaratılarak, öğrenenler, farklı milletler arasındaki yapısal eşitliğin sağlanması konusunda bilinçlendirilebilirler. Bu nedenle bir dil eğitimi, ırkçlık, cinsiyetçilik, heteroseksizm, dini hoşgörüsüzlük ve zenofobi konularına karşı bir duruş sergilemelidir. Bu tarz bir eğitimde, öğrenenler toplumlardaki baskı ve güç ilişkilerini eleştirel bir bakış açısıyla analiz etme şansına sahip olurlar. Bununla birlikte "ikinci dilin hem öğrenenlerinin hem de öğretmenlerinin kültürel farklılıkları anlamaları, insanların derinin altında tamamen aynı olmadıklarını açık bir şekilde idrak etmeleri gerekir. Gruplar ve kültürler arasında gerçek farklılıklar vardır. Bu farklılıkları algılamayı, takdir etmeyi ve her şeyden önce her insanın kişiliğine saygı duymayı ve değer vermeyi öğrenebiliriz" (Brown, 2000, s.180). Bütün bu kazanımların gerçekleşmesi için, eğitimcilerin pedagojik eğitimlerinin çokkültürlü eğitim odaklı verilmesi, ilk önce onların küresel vatandaş düzeyine yükseltilmesi ve pedagojik eğitimleri çerçevesinde edindikleri bu kazanımları, kendi dil sınfflarına yansıtabilmeleri ve en doğru şekilde aktarabilmeleri gerekmektedir. Bu çerçevede, kültürlerarası farklılıkların toplumlar için ayırıcı bir etken olarak değil tam aksine zenginlik olarak görülmesi gerektiği fikri üzerinde durulmalıdır.

Çok dillilik insanın davranışını şekillendirir. Farklı coğrafyaların farklı davranışları, farklı ifade yolları olduğunun farkına varan insan artık önyargılarla hareket edilmemesi gerektiğini anlar. Bu farkındalık sayesinde, dünyanın farklı insanlarının iletişim özelliklerine karşı daha duyarlı hale gelir. Tanımadıklarını tanımak için daha meraklı olur. Sertliklerini kaybeder ve daha toleranslı bireyler haline gelirler. Çok dilli kişiler daha fazla inisiyatif alırlar, daha zengin deneyimler yaşar ve başkalarını anlama noktasında daha iyi bir anlayışa sahip olurlar. Zira dünya hakkında çok daha fazla bilgi ve deneyime sahip olmuşlardır. Diğer bir kazanım ise, insan ne kadar dil konuşursa diğer dillerin edinimi daha kolay olacaktır. Yabancı dillerin insana getirdiği diğer bir özellik zihinsel jimnastiktir. Çok dilli insanlar sürekli yeni ifade araçları öğrenmeye mahkumdurlar. Bununla birlikte, kimse bir yabancı dile, o dili doğuştan edinen birisi gibi hakim olamaz. Ama sürekli kendisini geliştirebilir.

Her ne kadar çokdillilik ve çokkültürlülük toplumlar için bir zenginlik olarak görülse de bazen ciddi sorunlara da neden olabilmektedir. Bu sorun- 
ların altında yatan en tehlikeli düşünce ırkçlıktır. Bunu iki açıdan değerlendirmek mümkündür: Bir yandan gelişmiş ülkelerde göç sorununun giderek artması sebebiyle yabancıların birçoğu, bulundukları ülkenin dilini öğrenmektense kendi dillerini konuşan topluluklarla beraber olmayı tercih ederler. Böylece kendilerini ağırlayan ülkenin dilini öğrenme konusunda tembel ve yeteneksiz izlenimi uyandırırlar. Diğer yandan ise, bazı ülkelerde nüfusun çoğunluğu göçmenleri kabul etmek istemez. Bu tür ülkelerde göçmenler şayet dili öğrenmeye çalışırlarsa, bu kez de ülkeyi istila eden iş hırsızları veya sığınmacıları olarak adlandırılabilirler.

Çokkültürlü eğitim, ötekine karşı geliştirilen basmakalıpçı düşünce, önyargı, 1rkçılık, zenofobi ve bağnazlık gibi olumsuz düşüncelerin ortadan kalkmasına yardımcı olur. Bunun için kültürlerarasındaki farklılıklara değil benzerliklere odaklanmak daha yerinde bir davranış olacaktır. Çokkültürlü eğitim, öğrencilere kültürler arasındaki anlayışı ve iletişim becerilerini geliştirme fırsatı sunar. Öğrenciler güç ilişkileri, kimlik kavramları ve kültürel karmaşıklık ile ilgili zor soruları keşfederler. Kültür karmaşık ve dinamiktir, kimlikle aynı değildir, fakat kimliği ve bakış açısını etkileyebilir. Çokkültürlü eğitim anlayışı, çoğulcu, adil ve kapsayıcı bir toplumu teşvik eder. Öte yandan, belirli bir ırkın veya etnik kökenlinin, diğerlerinden daha düşük veya daha üstün olduğu inancı ırkçlık düşüncesini doğurur. Irkçılı̆̆n doğasını, etkilerini ve sonuçlarını anlamak, etkili bir şekilde mücadele etmek için çokkültürlü kapsayıcı bir eğitim gereklidir. Farklı ırktan, farklı kültür ve inançlara sahip insanların toplum içinde kendilerine yer bulmaları, eşit haklara sahip olmaları ve egemen olan kültürün hegemonyası altında ezilmemeleri, egemen kültürün vatandaşlarının farklı ırk, kültür ve inançlara sahip diğer insanlara bakışına ve yaklaşımına bağlıdır. "Çağdaş siyasi bir toplumda azınlık bir kültüre mensup bir ailenin ferdi olarak doğmak bir çocuk için, sadece bir dezavantaj ya da şanssızlıktan ibaret görülmemelidir. Yani, ailesi içerisinde toplumsal kültüründen farklı bir kültürün normları çerçevesinde yetişmek durumunda olan bir kimse, ya toplum dışında kalmak ya da kendi kültürünü, dinini, dilini, geleneksel giyim alışkanlıklarını terk etmek gibi bir seçimle karşı karşıya kalmamalıdır. Nasıl çoğunluğa mensup bir ailenin çocuğu gayet doğal bir biçimde kendi kültürel yaşantısını sürdürebilme olanağına sahipse, aynı siyasal toplumun vatandaşı olan diğeri de bu hakka sahip olmalıdır"(Balı, 2001, s.218). Irkçlık, insanları doğrudan veya dolaylı olarak 
hizmetlere erişmekten veya istihdam, eğitim, spor ve sosyal faaliyetlere katılmaktan alıkoyabilir. Bunun için kapsayıcı eğitim çokkültürlü yaşamda tarafların her insanın sahip olduğu yeme, içme, barınma, eğitim ve sağlık gibi temel hak ve özgürlüklerine ulaşmalarındaki ırkçılık engelini kaldırmada etkili bir yöntemdir.

Dil eğitiminde çokkültürlü anlayışı benimsemek, öğrencilerin dünyayı ve küreselleşmeyi merak etmelerine, küresel ve yerel ilişkilerin nasıl birbirine bağımlı olduklarını anlamalarına, küresel fırsatları tanımalarına ve bu firsatlar üzerinde hareket etme, ilerleme, küresel istikrar ve barışı sağlama becerilerine sahip olmalarına yardımcı olur. Çokkültürlü bir dil eğitimi yabancı bir dil öğretiminin yanı sıra, öğrenenin hayatını zenginleştirebilir ve farklı faaliyetlerde bulunmasına olanak vererek hızla küreselleşen bir dünyada, gelişime ve değişime bireysel ve toplumsal olarak katılmalarını sağlayabilir.

\section{Sonuç}

Küreselleşme, sadece ekonomi politikalarında değil, aynı zamanda eğitim politikalarında; iklim değişikliği, küresel güvenlik, salgın hastalıklar veya toplu göç gibi küresel önem taşıyan meselelere odaklanan küresel vatandaşlığa yönelik bir dizi oryantasyon çalışmasını da gerektirmektedir. Kültürel küreselleşme, farklı ülkeler arasında yabancı dillerin yaygın olarak uluslararası iletişim için kullanılmasını öngörmektedir. Yeni dünyada, eğitim sisteminin temel amacı, dünyanın sorunlarını çözmek için vasıflı profesyoneller yetiştirmektir. Gelişmekte olan pazarlarda çalışacak donanımda ve toplumsal sorunlara çözüm bulmaya katkıda bulunabilecek sosyal vicdana sahip bireyler yetiştirmek, eğitim politikalarını bu yönde düzenlemek, her devlete düşen görevlerden biridir. Çokkültürlü eğitimle geleceğin dünyasında, farklılıkları engel olarak görmenin önüne geçilecektir. Böylelikle insanlar birbirini daha iyi anlayıp birlikte barış içinde yaşamı tercih edeceklerdir. Her geçen gün biraz daha kaosa sürüklenen dünyanın daha yaşanılır olması ortak akıl ve bilinçle mümkün olacaktır. Sınırların kalkması dünyayı hor kullanma sınırsızlığı olarak görülmemelidir. Çokkültürlü eğitim, öteki kültür ve dillere hoşgörülü ve uzlaşmacı olmayı telkin eden bir anlayış olarak hergün biraz daha alan kazanmaktadır. İnsanlığın bir an önce harekete geçerek dünyayı tehdit eden herşeye karşı tavır alması kaçınılmazdır. Gelinen noktada, küresel sermayeyi küresel bilince dönüştürmek için herkes daha fazla özveri göstermeli ve sorumluluk üstlenmelidir. 


\title{
EXTENDED ABSTRACT
}

\section{Multiculturalism and Foreign Language Education in A Globalized World}

*

\author{
Elif Ateş - Halil Aytekin \\ Ondokuz Mayıs University
}

In a globalized world, inter-communal interaction has become inevitable with the removal of borders between people thanks to technology. The ease of communication and accessibility, commercial and individual relationships based on mutual communication and interaction, such as friendship, business partnership, education, have enabled people of different races to be in the same environment, act together or work together. So that any kind of work/action can be carried out with the citizens of another country by means of technology without having to go to the country where the person is living.

In today's world where international communication and interaction has become almost imperative, the necessity of knowing at least one foreign language has come to light and countries have started to regulate their education policies in this direction. In addition, it has become common concern of some countries to train global citizens who can act together against global problems for the planet. Nowadays, foreign language knowledge emerges as one of the most important criteria for the countries to have a say in the world of the future in international relations. Because communication takes place through language and acting together requires mutual understanding and therefore knowledge of the other's culture. In this context, the Council of Europe has developed and implemented a program that supports multicultural education, in addition to teaching some cultural elements of the target language while teaching a foreign language. In 2001, the Common European Framework of Reference for Languages, organized by the Council of Europe, focused on plurilingualism in an individual context and envisaged a foreign language education within the framework of the Action-Oriented Method, in which the learner is seen as a social actor. The text also underlines the concepts of multilingualism and multiculturalism in the social context and draws attention to similarities rather than differences. In this approach, besides the 
multilingualism in the social context, the knowledge of more than one foreign language in the individual context is pointed out.

In fact, learning a language in all aspects means learning the language used in the written works of the members of the speaking society as well as the language used in certain places and situations in their social lives. Indeed, it is the social life that creates the language. The learner who knows the culture of the foreign language he has learned and who is aware of the existence of different lifestyles has taken a step towards becoming a global citizen to multilingual and multicultural life. A multicultural understanding of language education provides information about the history and culture of different human communities, helping learners to have an idea of the culture of the target language, so that the learner is no stranger to the other culture. By creating awareness through multicultural education, learners can be made conscious of achieving structural equality between different nations. Therefore, language education should take a stand against racism, sexism, heterosexism, religious intolerance and zenophobia. In this type of education, learners have the opportunity to critically analyze the relations of oppression and power in societies. However, both the learners and teachers of the foreign language need to understand cultural differences and understand that people are not exactly the same under the skin. Multicultural education helps eliminate negative thoughts such as stereotypical thinking, prejudice, racism, zenophobia and bigotry developed against the other. Therefore, it would be more appropriate to focus on similarities rather than differences between cultures. Multicultural education offers students the opportunity to develop understanding and communication skills between cultures. Students explore difficult questions about power relations, concepts of identity and cultural complexity. The understanding of multicultural education promotes a pluralistic, fair and inclusive society. Multicultural and inclusion education is necessary to understand and effectively combat the nature, effects and consequences of racism. The fact that people of different races, cultures and beliefs have a place in society, have equal rights and not be crushed under the hegemony of the dominant culture depends on the views and approaches of the citizens of the dominant culture to other people with different races, cultures and beliefs.

Globalization requires a series of orientation studies aimed at global citizenship, focusing not only on economic policies but also on globally impor- 
tant issues such as education policies, climate change, global security, epidemics or mass migration. Nowadays, the main purpose of the education system is to train skilled professionals to solve the problems of the global world. It is one of the duties of every country to regulate education policies in this direction and to train individuals who are equipped with social conscience and who can contribute to finding solutions to social problems. With multicultural education, it will be prevented to see differences as obstacles in the world of the future. Thus, people will understand each other better and prefer to live together in peace. It will be possible with the common mind and consciousness to make the world more livable place.

\section{Kaynakça / References}

Andriuškevičienè, J. ve Kazlauskaitè, D.( 2019). Quelles langues apprendre? Choix des langues étrangères À L'université Vytautas Magnus. (http://www.goethe.de/ges/spa/prj/sog/mup/fr3249600.htm).

Balı, A, Ş. (2001). Çokkültürlülük ve sosyal adalet "öteki" ile barış içinde birlikte yaşamak. Konya: Çizgi Kitabevi Yayınları.

Banks, J, A., ve Banks, C .A .M. (2007). Multicultural education: Issues and perspectives (7th ed.). Hoboken, NJ: Wiley.

Brown, D. H. (2000). Principles of language learning $\mathcal{E}$ teaching. (4th ed.). New York: Longman.

Ethnologue: www.ethnologue.com/statistics/size

İmer, K. (1990). Dil ve toplum. Ankara: Gündoğan Yayınları.

İsen, G.-Batmaz, V., (2002). Ben ve toplum. İstanbul: Om Yayınları.

Labov, W. (2010). Principles of Linguistic Change: Cognitive and Cultural Factors. Hoboken, NJ: Wiley-Blackwell.

MEB Talim ve Terbiye Kurulu Başkanlığ Çeviri Komisyonu (2009). Diller İçin Avrupa Ortak Başvuru Metni Öğrenme-Öğretme-Değerlendirme, Talim Terbiye Kurulu Başkanlığı Yayınları, Ankara.

Şafak Balı, A. (2001). Çokkültürlülük ve sosyal adalet "öteki" ile barış içinde birlikte yaşamak. Konya: Çizgi Kitabevi Yayınları.

Yıldırım, A. (2011). Eleştirel pedagoji, Paulo Freire ve lvan Illich'in eğitim anlayışı üzerine. Ankara : Anı Yayıncılık.

Goethe. (t.y) Plurilinguisme. 11.11.2019 tarihinde http://www.goethe.de/ges/spa/prj/sog/mup/fr3249600.htm adresinden erişilmiştir. 


\section{Kaynakça Bilgisi / Citation Information}

Ateş, E. ve Aytekin, H. (2020). Küreselleşen dünyada çokkültürlülük ve yabancı dil eğitimi. OPUS-Uluslararası Toplum Araştırmaları Dergisi, 15(26), 4563-4579. DOI: 10.26466/opus. 651385 